\title{
Testes cutâneos de hipersensibilidade imediata com o evoluir da idade
}

\author{
Positive skin test and age
}

\begin{abstract}
Wilma Carvalho Neves Forte ${ }^{1}$, Fábio Ferreira de Carvalho Júnior ${ }^{2}$, Wilson Diogo Fernandes Filho ${ }^{3}$, Elisabete Shibata ${ }^{3}$, Luciana S Henriques ${ }^{3}$, Roberto Antonio Mastroti ${ }^{4}$, Marilda da Silva Guedes ${ }^{5}$
\end{abstract}

\section{Resumo}

Objetivo: avaliação da positividade aos testes cutâneos de hipersensibilidade imediata em crianças com asma brônquica e/ou rinite alérgica em diferentes faixas etárias.

Casuística e Métodos: foi observada a positividade aos testes cutâneos de hipersensibilidade imediata, por testes de puntura, frente a diferentes alérgenos de mesma procedência: poeira total e Dermatophagóides sp, Dermatophagoides pteronyssinus, Dermatophagoides farinae e Blomia tropicalis, Penicillium sp, Alternaria alternata, Cladosporium herbarium, Aspergillus fumigatus, grama bermuda, capim de pasto, epitélio de cão, epitélio de gato, penas, Blatella germanica, lã. Foram selecionadas 713 crianças divididas em grupos conforme a faixa etária: grupo I (6 a 11 meses), II (1 a 3 anos e 11 meses), III ( 4 a 8 anos e 11 meses) e IV ( 9 a 15 anos). Para análise estatística utilizou-se o cálculo do qui-quadrado.

Resultados: o total de diferenças significativas entre os vários grupos foi: I e II = 5; II e III = 5; II e IV = 5; III e IV = 6; I e III = 10 e I e IV $=10$

Conclusão: concluiu-se que a positividade ao teste de hipersensibilidade imediata foi maior com o evoluir da idade, havendo positividade já aos doze meses de vida, sendo esta positividade significativamente maior a partir de quatro anos de idade.

J Pediatr (Rio J) 2001; 77 (2): 112-8: hipersensibilidade imediata, testes cutâneos, alérgenos, grupos etários.

\section{Introdução}

O diagnóstico de atopia de vias aéreas é baseado fundamentalmente no quadro clínico e na anamnese individual e familiar. Para complementação diagnóstica são importan-

1. Profa. Adjunto de Imunologia da Faculdade de Ciências Médicas da Santa Casa de São Paulo (FCMSCSP) e Responsável pelo Setor de Alergia da Santa Casa de São Paulo (SCMSP).

2. Mestre em Pediatria e Assistente do Setor de Alergia Pediátrica da SCMSP.

3. Residentes do Setor de Alergia Pediátrica da SCMSP

4. Prof. Adjunto de Cirurgia Infantil e Diretor do Departamento de Pediatria da SCMSP.

5. Mestre em Medicina e Profa. Assistente do Departamento de Medicina Social da FCMSCSP.

\begin{abstract}
Objective: to evaluate positive responses to skin tests for immediate hypersensitivity to allergens in children with asthma and rhinitis at different ages.

Method: we observed positive skin test reactivity in prick tests using fifteen allergens of same origin (total dust and Dermatophagoides sp.; Dermatophagoides pteronyssinus; Dermatophagoides farinae; Blomia tropicalis; Penicillium sp; Alternariaalternata; Cladosporium herbarium; Aspergillus fumigatus; Bermuda grass; forage grass; dog and cat epithelia; feathers; Blatella germanica and wool). We placed 713 selected patients into different age groups - Group I: 6 to 11 months; Group II: 1 to 3 years and 11 months; Group III: 4 to 8 years and 11 months; and Group IV: 9 to 15 years. We used the chi-square test for statistical analysis.

Results: the total significant differences between these groups were: $\mathrm{I}$ to $\mathrm{II}=5$; II to III $=5$; II to IV $=5$; III to $\mathrm{IV}=6$; $\mathrm{I}$ to $\mathrm{III}=10$; and I to IV $=10$.

Conclusion: skin test reactivity is acquired progressively with age, and can be observed as early as at 12 months. Reactivity is significantly more positive from the age of 4 on.
\end{abstract}

J Pediatr (Rio J) 2001; 77 (2): 112-8: immediate hypersensitivity, skin tests, allergens, age groups.

tes a positividade aos testes cutâneos, níveis séricos elevados de IgE e provas de função pulmonar ${ }^{1}$.

Provas de função pulmonar, como pico de fluxo expiratório, podem estar reduzidas na asma brônquica, porém sua normalidade não afasta a doença.

Níveis séricos de $\operatorname{IgE}$ são úteis, porém são de alto custo e estão elevados em outras situações clínicas como parasitoses intestinais de ciclo biológico extra-intestinal, situação esta tão freqüente em nosso meio que torna difícil a realização de curvas-padrão para esta imunoglobulina. Soma-se o fato de que muitas vezes a IgE sérica está normal mesmo em 
indivíduos atópicos, como ocorre em $20 \%$ dos casos de rinite alérgica, provavelmente pelo fato de que os métodos disponíveis quantifiquem a IgE sérica livre e não a unida a mastócitos e basófilos, a qual é a principal responsável no processo atópico ${ }^{2}$.

As provas cutâneas de hipersensibilidade imediata são de fácil realização e auxiliam muito no diagnóstico etiológico das atopias, desde que realizadas por profissional especializado.

Existem poucos trabalhos na literatura indicando a idade ideal para o início de realização de testes cutâneos. Entre crianças atópicas e não atópicas a reatividade à histamina em atópicos é mais precoce. Crianças aos três anos apresentam reação à histamina com $61 \%$ do diâmetro de adultos ${ }^{4}$.

Estudos sobre a positividade a diferentes alérgenos sugerem que abaixo dos quatro anos de idade os testes cutâneos não teriam tanto valor ${ }^{5}$. A positividade a testes cutâneos seria menor na criança até quatro anos de idade, atingindo maior positividade desde a adolescência até a faixa de adultos jovens, seguida de declínio com a idade.

No Brasil, diversos estudos ${ }^{7-10}$ mostram que o Dermatophagoides pteronyssinus é o ácaro mais freqüentemente envolvido na gênese de doenças atópicas, seguido por Dermatophagoides farinae e a Blomia tropicalis, embora possam existir diferenças regionais nesta incidência.

É importante conhecer em nosso meio a positividade aos testes cutâneos e identificar a partir de que idade estes testes teriam mais valor no diagnóstico etiológico das atopias.

\section{Objetivo}

Avaliar a positividade a testes cutâneos de hipersensibilidade imediata aos alérgenos em crianças com asma brônquica e/ou rinite alérgica em diferentes faixas etárias.

\section{Métodos}

Foram selecionados durante um período de dez meses, crianças encaminhadas ao Ambulatório de Alergia do Departamento de Pediatria da Santa Casa de Misericórdia de São Paulo, desde que atendessem aos critérios de seleção. As crianças, quando encaminhadas ao Ambulatório, eram avaliadas pela mesma equipe e, quando enquadravam-se nos critérios, eram incluídas no estudo. As demais crianças atendidas foram igualmente acompanhadas, porém não incluídas no estudo.

Os critérios utilizados para seleção dos pacientes foram: repetição de sinais e sintomas alérgicos de vias aéreas, antecedentes familiares de atopias, níveis séricos elevados de $\operatorname{IgE}^{11}$, acompanhados de três exames protoparasitológicos negativos; foram excluídas crianças que estavam fazendo uso de corticosteróides ou anti-histamínicos nos últimos 21 dias ou que apresentassem dermatite na área submetida ao teste.
Nas crianças selecionadas realizou-se o teste de puntura (prick test) de leitura imediata, fazendo-se inoculação no antebraço direito, no período da manhã e com leitura após 15 minutos, utilizando-se conjuntos de puntores plásticos para cada criança e num mesmo paciente puntores diferentes para cada alérgeno Todos os extratos alergênicos tiveram a mesma procedência (Aristeg ${ }^{\circledR}$ ), padronizados em Ubt.

Foram utilizados quinze aeroalérgenos diferentes: poeira total e Dermatophagóides sp, Dermatophagoides pteronyssinus, Dermatophagoides farinae e Blomia tropicalis, Penicillium sp., Alternaria alternata, Cladosporium herbarium, Aspergillus fumigatus, grama bermuda, capim de pasto, epitélio de cão, epitélio de gato, penas, Blatella germanica e lã. Em todos os pacientes foi realizado controle positivo com cloridrato de histamina e controle negativo com solução salina. A positividade ao teste era considerada quando a aeroalérgeno apresentasse reação igual ou maior do que $3 \mathrm{~mm}$ e maior ou igual a histamina, além de reação negativa à solução salina. A leitura dos testes foi sempre realizada por três dos componentes do estudo, segundo padronização do Setor de Alergia Pediátrica.

A IgE foi determinada através de ELISA, em UI/ml ${ }^{10}$.

Tais exames são utilizados sempre que necessários no Setor de Alergia Pediátrica e são aprovados pelo Comitê de Ética da Instituição. Este estudo foi aprovado pelo Comitê de Ética da Instituição.

$\mathrm{Na}$ análise estatística foi feita a comparação da positividade nas diferentes faixas etárias e em cada faixa etária, comparando-se com a positividade para os diferentes alérgenos. O método estatístico utilizado foi o cálculo do quiquadrado $\left(c^{2}\right)$ e nível de significância (p). O EPI-INFO 6.2 foi usado como programa estatístico. Foram considerados como significativos valores de $\mathrm{c}^{2}>2$ e com $\mathrm{p}<0,05(5 \%)$.

\section{Resultados}

No período selecionado foram encaminhadas para avaliação 820 crianças (entre 0 e 16 anos incompletos); destas, $713(86,9 \%)$ foram incluídas no estudo, enquanto 107 $(13,1 \%)$ não se enquadravam nos critérios de inclusão.

Entre as crianças estudadas, $421(59,1 \%)$ eram do sexo masculino e 291 (40,9\%) do sexo feminino. 355(49,8\%) crianças apresentavam asma leve, $84(11,8 \%)$ asma moderada, $102(14,3 \%)$ asma grave e $418(58,7 \%)$ rinite alérgica.

As 713 crianças selecionadas foram divididas em quatro grupos segundo a faixa etária: grupo I: de 6 a 11 meses (38 crianças); II: de 1 a 3 anos e 11 meses (113 crianças); III: de 4 a 8 anos e 11 meses ( 275 crianças); e IV: de 9 a 15 anos (287 crianças). Foram avaliadas um total de 4.278 punturas. Nenhuma criança apresentou reações locais ou sistêmicas durante ou após o teste.

Os resultados estão apresentados sob a forma de tabelas. Os valores observados para IgE sérica nas diferentes 
faixas etárias encontram-se expressos na Tabela 1 e os resultados dos testes cutâneos estão descritos na Tabela 2. Os resultados do cálculo do Qui-quadrado para testes positivos e negativos nas diferentes faixas etárias encontram-se nas Tabelas 3, 4, 5, 6, 7 e 8. Na Tabela 9 está a comparação entre o número de testes que apresentam diferença significativa pelo cálculo de qui-quadrado nos diferentes grupos. Somente são considerados como significativos valores de $\mathrm{p}<0,05$ e com $\mathrm{c}^{2}>2$, sendo então expressos $\operatorname{com}(*)$.

Tabela 1 - Valores de IgE (UI/ml) distribuídos por faixa etária

\begin{tabular}{llcc}
\hline Grupo & Faixa etária & $\begin{array}{c}\text { Média } \\
\text { Geométrica }\end{array}$ & $\begin{array}{c}\text { Desvio- } \\
\text { Padrão }\end{array}$ \\
\hline I & 6 a 11 meses & 68,6 & 49,6 \\
II & 1 a 3 anos e 11 meses & 316,1 & 523,0 \\
III & 4 a 8 anos e 11 meses & 694,6 & 730,5 \\
IV & 9 a 15 anos & $1.270,0$ & $1.327,4$ \\
\hline
\end{tabular}

A análise dos resultados mostra ainda que testes cutâneos para poeira + Dermatophagoides, Dermatophagoides sp. elou Dermatophagoides pteronyssinus mostram positividade com diferença significativa (*) nos grupos II, III, IV (Tabelas 2 a 8).

A Tabela 9 mostra o total das diferenças significativas nos diferentes grupos etários. Assim, na Tabela 3, considerando-se poeira + Dermatophagoides, Dermatophagoides pteronyssinus, capim de pasto, epitélio de gato e penas, observa-se um total de 5 diferenças significativas entre os grupos I e II estudados.

\section{Discussão}

O método escolhido para avaliar a hipersensibilidade imediata foi o teste de puntura, por apresentar baixa ocorrência de efeitos adversos ${ }^{12}$ e por ter maior positividade em relação aos testes intradérmicos. Foram utilizados puntores plásticos por serem mais fidedignos de penetração subcutânea e um puntor para cada alérgeno e para cada paciente, evitando-se falsos positivos. Os extratos foram da mesma procedência para que os resultados pudessem ser compara$\operatorname{dos}^{13}$. O antebraço foi a região escolhida por ser a mais sensível ${ }^{14}$, e o período da manhã, por acreditar-se que devido ao ciclo circadiano haja maior positividade neste horário ${ }^{15}$.

Foram excluídos pacientes com uso prévio de antihistamínicos e corticosteróides por 21 dias, tentando-se eliminar falsos negativos, embora os autores nem sempre sejam unânimes quanto ao uso de corticosteróides invalidando testes cutâneos ${ }^{16}$ e muitas vezes orientando um tempo menor sem uso de anti-histamínicos para realização do exame ${ }^{17,18}$. Só foram incluídas crianças apresentando níveis aumentados de IgE para exclusão de pacientes com rinites e/ou broncoespasmo não mediados por IgE.

Testes cutâneos (prick test) refletem hipersensibilidade imediata do tipo I. Atopias dependem de uma série de eventos. Alérgenos levam à formação de IgE específica que se une a mastócitos e basófilos, tornando estas células sensibilizadas. Em um segundo contato com o mesmo alérgeno haverá união deste à IgE de mastócitos e basófilos,

Tabela 2 - Total de crianças com testes positivos de acordo com a faixa etária

\begin{tabular}{|c|c|c|c|c|c|c|c|c|}
\hline \multirow{2}{*}{$\begin{array}{l}\text { Grupos } \\
\text { Testes cutâneos }\end{array}$} & \multicolumn{2}{|c|}{$\mathbf{I}$} & \multicolumn{2}{|c|}{ II } & \multicolumn{2}{|c|}{ III } & \multicolumn{2}{|c|}{ IV } \\
\hline & + & - & + & - & + & - & + & - \\
\hline Poeira + Dermatophagoides & 6 & 32 & 39 & 74 & 103 & 172 & 139 & 148 \\
\hline Dermatophagoides pteronyssinus & 5 & 33 & 38 & 75 & 80 & 195 & 107 & 180 \\
\hline Dermatophagoides farinae & 2 & 36 & 15 & 98 & 53 & 222 & 65 & 222 \\
\hline Blomia tropicalis & 3 & 35 & 17 & 96 & 40 & 235 & 59 & 228 \\
\hline Penicillium sp. & 3 & 35 & 16 & 97 & 32 & 243 & 64 & 223 \\
\hline Aspergillus fumigatus & 2 & 36 & 13 & 100 & 26 & 249 & 35 & 252 \\
\hline Alternaria alternata & 4 & 34 & 12 & 101 & 26 & 249 & 46 & 241 \\
\hline Cladosporium herbarium & 3 & 35 & 17 & 96 & 25 & 250 & 33 & 254 \\
\hline Capim de pasto & 3 & 35 & 14 & 99 & 22 & 253 & 29 & 258 \\
\hline Grama bermuda & 2 & 36 & 17 & 96 & 27 & 248 & 27 & 260 \\
\hline Epitélio de gato & 3 & 35 & 23 & 90 & 39 & 236 & 41 & 246 \\
\hline Epitélio de cão & 2 & 36 & 23 & 90 & 42 & 233 & 53 & 234 \\
\hline Lã & 3 & 35 & 13 & 100 & 24 & 251 & 21 & 266 \\
\hline Penas & 3 & 35 & 15 & 98 & 26 & 249 & 38 & 249 \\
\hline Blatella germanica & 3 & 35 & 11 & 102 & 26 & 249 & 20 & 267 \\
\hline Total de testes positivos(+) e negativos(-) & 47 & 523 & 283 & 1.412 & 591 & 3.534 & 777 & 3.528 \\
\hline
\end{tabular}

$c^{2}=3,84$ 
Tabela 3 - Comparação entre os grupos I e II

\begin{tabular}{|c|c|c|c|c|c|c|}
\hline \multirow{2}{*}{$\begin{array}{l}\text { Grupos } \\
\text { Testes cutâneos }\end{array}$} & \multicolumn{2}{|c|}{ I } & \multicolumn{2}{|c|}{ II } & \multirow[b]{2}{*}{$c^{2}$} & \multirow[b]{2}{*}{$\mathbf{p}$} \\
\hline & + & - & + & - & & \\
\hline Poeira + Dermatophagoides & 6 & 32 & 39 & 74 & 4,76 & $0,02 *$ \\
\hline Dermatophagoides pteronyssinus & 5 & 33 & 38 & 75 & 2,85 & $0,01 *$ \\
\hline Dermatophagoides farinae & 2 & 36 & 15 & 98 & 1,82 & 0,17 \\
\hline Blomia tropicalis & 3 & 35 & 17 & 96 & 1,26 & 0,26 \\
\hline Penicillium sp. & 3 & 35 & 16 & 97 & 1,01 & 0,31 \\
\hline Aspergillus fumigatus & 2 & 36 & 13 & 100 & 1,24 & 0,26 \\
\hline Alternaria alternata & 4 & 34 & 12 & 101 & 2,60 & 0,98 \\
\hline Cladosporium herbarium & 3 & 35 & 17 & 96 & 1,26 & 0,26 \\
\hline Capim de pasto & 3 & 35 & 14 & 99 & 5,75 & $0,04 *$ \\
\hline Grama bermuda & 2 & 36 & 17 & 96 & 2,47 & 0,11 \\
\hline Epitélio de gato & 3 & 35 & 23 & 90 & 3,09 & 0,07 \\
\hline Epitélio de cão & 2 & 36 & 23 & 90 & 4,68 & $0,03 *$ \\
\hline Lã & 3 & 35 & 13 & 100 & 3,91 & 0,53 \\
\hline Penas & 3 & 35 & 15 & 98 & 7,83 & $0,04 *$ \\
\hline Blatella germanica & 3 & 35 & 11 & 102 & 1,14 & 0,73 \\
\hline Total de testes positivos(+) e negativos(-) & 47 & 523 & 283 & 1.412 & 1,63 & \\
\hline
\end{tabular}

* diferença significativa

influxo de cálcio e degranulação destas células, com liberação de mediadores pré-formados como histamina e neoformados como prostaglandinas e leucotrienos. A inoculação cutânea de alérgeno em paciente com mastócitos e basófilos especificamente sensibilizados leva de imediato à liberação de mediadores responsáveis por máculo-pápulas formadas. Assim, na presença de mastócitos sensibilizados e resposta inflamatória em pele, haverá positividade ao teste cutâneo.
Nossas observações mostram pelo método do cálculo de Qui-quadrado positividade significativa (*) aos testes cutâneos de leitura imediata a partir dos doze meses de idade. Essa positividade torna-se mais significativa (*) a partir de quatro anos, quando o número de testes positivos passa a ser maior, conforme mostra o total de diferenças significativas (*) na comparação entre os grupos I e II = 5 e I e IV $=10$. Assim há aumento de positividade quando se comparam os grupos de maior idade aos de menor idade.

Tabela 4 - Comparação entre os grupos I e III

\begin{tabular}{|c|c|c|c|c|c|c|}
\hline \multirow{2}{*}{$\begin{array}{l}\text { Grupos } \\
\text { Testes cutâneos }\end{array}$} & \multicolumn{2}{|c|}{$\mathbf{I}$} & \multicolumn{2}{|c|}{ III } & \multirow[b]{2}{*}{$c^{2}$} & \multirow[b]{2}{*}{$\mathbf{p}$} \\
\hline & + & - & + & - & & \\
\hline Poeira + Dermatophagoides & 6 & 32 & 103 & 172 & 6,90 & $0,01 *$ \\
\hline Dermatophagoides pteronyssinus & 5 & 33 & 80 & 195 & 4,28 & $0,04 *$ \\
\hline Dermatophagoides farinae & 2 & 36 & 53 & 222 & 4,52 & 0,33 \\
\hline Blomia tropicalis & 3 & 35 & 40 & 235 & 1,24 & 0,26 \\
\hline Penicillium sp. & 3 & 35 & 32 & 243 & 4,70 & $<0,05^{*}$ \\
\hline Aspergillus fumigatus & 2 & 36 & 26 & 249 & 0,72 & 0,39 \\
\hline Alternaria alternata & 4 & 34 & 26 & 249 & 4,42 & $0,04 *$ \\
\hline Cladosporium herbarium & 3 & 35 & 25 & 250 & 5,86 & $0,01 *$ \\
\hline Capim de pasto & 3 & 35 & 22 & 253 & 5,03 & $0,01 *$ \\
\hline Grama bermuda & 2 & 36 & 27 & 248 & 8,23 & $0,03 *$ \\
\hline Epitélio de gato & 3 & 35 & 39 & 236 & 1,14 & 0,28 \\
\hline Epitélio de cão & 2 & 36 & 42 & 233 & 2,77 & 0,10 \\
\hline Lã & 3 & 35 & 24 & 251 & 2,93 & 0,08 \\
\hline Penas & 3 & 35 & 26 & 249 & 9,66 & $0,02 *$ \\
\hline Blatella germanica & 3 & 35 & 26 & 249 & 9,66 & $0,02 *$ \\
\hline Total de testes positivos(+) e negativos(-) & 47 & 523 & 59 & 3.534 & 1,05 & \\
\hline
\end{tabular}

* diferença significativa 
Tabela 5 - Comparação entre os grupos I e IV

\begin{tabular}{|c|c|c|c|c|c|c|}
\hline \multirow{2}{*}{$\begin{array}{l}\text { Grupos } \\
\text { Testes cutâneos }\end{array}$} & \multicolumn{2}{|c|}{ I } & \multicolumn{2}{|c|}{ IV } & \multirow[b]{2}{*}{$c^{2}$} & \multirow[b]{2}{*}{$\mathbf{p}$} \\
\hline & + & - & + & - & & \\
\hline Poeira + Dermatophagoides & 6 & 32 & 139 & 148 & 14,47 & $<0,01 *$ \\
\hline Dermatophagoides pteronyssinus & 5 & 33 & 107 & 180 & 8,64 & $<0,01 *$ \\
\hline Dermatophagoides farinae & 2 & 36 & 65 & 222 & 6,19 & $0,01 *$ \\
\hline Blomia tropicalis & 3 & 35 & 59 & 228 & 3,48 & 0,05 \\
\hline Penicillium sp. & 3 & 35 & 64 & 223 & 4,25 & $0,04 *$ \\
\hline Aspergillus fumigatus & 2 & 36 & 35 & 252 & 1,59 & 0,20 \\
\hline Alternaria alternata & 4 & 34 & 46 & 241 & 7,80 & $0,04 *$ \\
\hline Cladosporium herbarium & 3 & 35 & 33 & 254 & 4,42 & $<0,05^{*}$ \\
\hline Capim de pasto & 3 & 35 & 29 & 258 & 1,84 & 0,07 \\
\hline Grama bermuda & 2 & 36 & 27 & 260 & 7,09 & $0,04 *$ \\
\hline Epitélio de gato & 3 & 35 & 41 & 246 & 1,17 & 0,28 \\
\hline Epitélio de cão & 2 & 36 & 53 & 234 & 4,16 & 0,41 \\
\hline Lã & 3 & 35 & 21 & 266 & 1,63 & 0,20 \\
\hline Penas & 3 & 35 & 38 & 249 & 8,69 & $0,03 *$ \\
\hline Blatella germanica & 3 & 35 & 20 & 267 & 4,37 & $<0,01 *$ \\
\hline Total de testes positivos(+) e negativos(-) & 47 & 523 & 777 & 3.528 & 2,30 & \\
\hline
\end{tabular}

* diferença significativa

Sabe-se que crianças abaixo de cinco anos apresentam menor atividade quimiotática e fagocitária por monócitos, quando comparadas a crianças maiores ${ }^{19,20}$. É provável que haja uma correlação entre estas atividades de fagócitos e apresentação antigênica por tais células. Linfócitos $\mathrm{T}$ auxiliares com receptores de células T (TCR), altamente específicos, glicoproteínas CD3 e CD4 reúnem-se de forma não covalente aos antígenos. As moléculas de adesão LFA1 e CD2 auxiliam ainda este processo. Monócitos e macró- fagos expressando HLA classe II, ICAM-1 e B27 apresentam epítopos a linfócitos T auxiliares, tornando estas células ativadas. Em indivíduos atópicos linfócitos T ativados por alérgenos sintetizam predominantemente interleucinas 4, 5, 6, 10 e 13, que caracterizam presença de linfócitos T helper 2. Estudos em asmáticos mostram uma maior positividade a multialérgenos em crianças maiores, sugerindo que a memória imunológica de T helper 2 para alérgenos inalatórios se estabeleça com o decorrer da idade ${ }^{21}$. As

Tabela 6 - Comparação entre os grupos II e III

\begin{tabular}{lccccccc}
\hline Grupos & \multicolumn{2}{c}{ II } & \multicolumn{3}{c}{ III } & & \\
Testes cutâneos & + & - & + & - & $\mathbf{c}^{\mathbf{2}}$ & $\mathbf{p}$ \\
\hline Poeira + Dermatophagoides & 39 & 74 & 103 & 172 & 2,98 & 0,06 \\
Dermatophagoides pteronyssinus & 38 & 75 & 80 & 195 & 7,79 & $0,04^{*}$ \\
Dermatophagoides farinae & 15 & 98 & 53 & 222 & 1,99 & 0,15 \\
Blomia tropicalis & 17 & 96 & 40 & 235 & 1,58 & 0,09 \\
Penicillium sp. & 16 & 97 & 32 & 243 & 4,70 & $<0,05^{*}$ \\
Aspergillus fumigatus & 13 & 100 & 26 & 249 & 3,72 & 0,05 \\
Alternaria alternata & 12 & 101 & 26 & 249 & 1,23 & 0,07 \\
Cladosporium herbarium & 17 & 96 & 25 & 250 & 2,94 & 0,08 \\
Capim de pasto & 14 & 99 & 22 & 253 & 1,83 & 0,17 \\
Grama bermuda & 17 & 96 & 27 & 248 & 2,75 & 0,14 \\
Epitélio de gato & 23 & 90 & 39 & 236 & 2,27 & 0,13 \\
Epitélio de cão & 23 & 90 & 42 & 233 & 1,48 & 0,22 \\
Lã & 13 & 100 & 24 & 251 & 7,16 & $0,04^{*}$ \\
Penas & 15 & 98 & 26 & 249 & 1,24 & 0,26 \\
Blatella germanica & 11 & 102 & 26 & 249 & $7,27 *$ & $0,04^{*}$ \\
\hline Total de testes positivos(+) e negativos(-) & 283 & 1.412 & 591 & 3.534 & 3,50 & \\
\hline
\end{tabular}

${ }^{*}$ diferença significativa 
Tabela 7 - Comparação entre os grupos II e IV

\begin{tabular}{lccccccc}
\hline Grupos & \multicolumn{3}{c}{ II } & \multicolumn{7}{c}{ IV } & & \\
Testes cutâneos & + & - & + & - & $\mathbf{c}^{\mathbf{2}}$ & p \\
\hline Poeira + Dermatophagoides & 39 & 74 & 139 & 148 & 6,36 & $0,01^{*}$ \\
Dermatophagoides pteronyssinus & 38 & 75 & 107 & 180 & 0,46 & 0,49 \\
Dermatophagoides farinae & 15 & 98 & 65 & 222 & 4,45 & $0,03^{*}$ \\
Blomia tropicalis & 17 & 96 & 59 & 228 & 1,60 & 0,20 \\
Penicillium sp. & 16 & 97 & 64 & 223 & 3,35 & 0,07 \\
Aspergillus fumigatus & 13 & 100 & 35 & 252 & 3,66 & 0,05 \\
Alternaria alternata & 12 & 101 & 46 & 241 & 1,91 & 0,16 \\
Cladosporium herbarium & 17 & 96 & 33 & 254 & 9,32 & $0,03^{*}$ \\
Capim de pasto & 14 & 99 & 29 & 258 & 0,44 & 0,50 \\
Grama bermuda & 17 & 96 & 27 & 260 & 2,63 & 0,10 \\
Epitélio de gato & 23 & 90 & 41 & 246 & 2,22 & 0,13 \\
Epitélio de cão & 23 & 90 & 53 & 234 & 1,87 & $<0,01^{*}$ \\
Lã & 13 & 100 & 21 & 266 & 1,82 & 0,17 \\
Penas & 15 & 98 & 38 & 249 & 8,11 & $0,01^{*}$ \\
Blatella germanica & 11 & 102 & 20 & 267 & 8,67 & $0,03^{*}$ \\
\hline Total de testes positivos(+) e negativos(-) & 283 & 1.412 & 777 & 3.528 & 1,03 & \\
\hline
\end{tabular}

* diferença significativa

interleucinas 4 e 5 apresentam correlação com história de atopia familiar aos 2 anos e com atopia individual em pacientes acima de 5 anos de idade ${ }^{22}$. Níveis de IgE atingem pico máximo entre 9 e $19 \operatorname{anos}^{4,23}$. Todos estes dados contribuíram para menor positividade dos testes em crianças pequenas.

Por outro lado, é muito provável que a menor exposição a alérgenos seja responsável por uma menor positividade em baixa idade, pois pesquisadores observaram que a reatividade para concentrações maiores de histamina já está presente aos três meses de idade ${ }^{2}$.
Nossos resultados, mostrando testes cutâneos com positividade significativa a partir de doze meses de idade, são coerentes com os trabalhos da literatura que indicam a possibilidade de a criança de baixa idade poder apresentar testes positivos, desde que sensibilizada. Contribui para esta hipótese o encontro de maior positividade para poeira +Dermatophagoides, Dermatophagoides sp. elou Dermatophagoides pteronyssinus em todos os grupos, inclusive no grupo I, uma vez que estes alérgenos são os que mais precocemente sensibilizam. Da mesma forma, nossos resultados que mostram positividade mais significativa aos tes-

Tabela 8 - Comparação entre os grupos III e IV

\begin{tabular}{lccccccc}
\hline Grupos & \multicolumn{2}{c}{ III } & \multicolumn{3}{c}{ IV } & & \\
Testes cutâneos & + & - & + & - & $\mathbf{c}^{\mathbf{2}}$ & p \\
\hline Poeira + Dermatophagoides & 103 & 172 & 139 & 148 & 6,90 & $<0,01^{*}$ \\
Dermatophagoides pteronyssinus & 80 & 195 & 107 & 180 & 4,24 & $0,04^{*}$ \\
Dermatophagoides farinae & 53 & 222 & 65 & 222 & 9,64 & $0,03^{*}$ \\
Blomia tropicalis & 40 & 235 & 59 & 228 & 3,49 & 0,06 \\
Penicillium sp & 32 & 243 & 64 & 223 & 11,27 & $<0,01^{*}$ \\
Aspergillus fumigatus & 26 & 249 & 35 & 252 & 1,09 & 0,29 \\
Alternaria alternata & 26 & 249 & 46 & 241 & 5,43 & $0,02^{*}$ \\
Cladosporium herbarium & 25 & 250 & 33 & 254 & 0,88 & 0,34 \\
Capim de pasto & 22 & 253 & 29 & 258 & 7,54 & $0,04^{*}$ \\
Grama bermuda & 27 & 248 & 27 & 260 & 2,72 & 0,08 \\
Epitélio de gato & 39 & 236 & 41 & 246 & 1,24 & 0,09 \\
Epitélio de cão & 42 & 233 & 53 & 234 & 1,02 & 0,31 \\
lã & 24 & 251 & 21 & 266 & 3,79 & 0,05 \\
Penas & 26 & 249 & 38 & 249 & 1,99 & 0,15 \\
Blatella germanica & 26 & 249 & 20 & 267 & 1,15 & 0,28 \\
\hline Total de testes positivos(+) e negativos(-) & 591 & 3.534 & 777 & 3.528 & 1,43 & \\
\hline
\end{tabular}

* diferença significativa 
Tabela 9 - Total das diferenças significativas (*) nas comparações dos diferentes grupos

\begin{tabular}{cc}
\hline Grupos & Total \\
\hline Grupos I e II & 5 \\
Grupos II e III & 5 \\
Grupos II e IV & 5 \\
Grupos III e IV & 6 \\
Grupos I e III & 10 \\
Grupos I e IV & 10 \\
\hline
\end{tabular}

tes cutâneos a partir dos quatro anos são coerentes com os estudos sobre maturação do sistema imunológico e da resposta inflamatória com o evoluir da idade.

Algum grau de imaturidade do sistema imunológico associado a menor exposição alergênica em crianças de baixa idade podem ser responsáveis pelo fato de a positividade aos testes cutâneos aumentar progressivamente com a idade, uma vez que a sensibilização demanda tempo e grau de exposição aos alérgenos.

\section{Conclusão}

Concluímos que a positividade de testes cutâneos de hipersensibilidade imediata frente à poeira total e Dermatophagóides sp., Dermatophagoides pteronyssinus, Dermatophagoides farinae e Blomia tropicalis, Penicillium sp., Alternaria alternata, Cladosporium herbarium, Aspergillus fumigatus, grama bermuda, capim de pasto, epitélio de cão, epitélio de gato, penas, Blatella germanica e lã são significativos a partir de doze meses, tornando-se a positividade consistentemente significativa a partir dos quatro anos de idade, em crianças atópicas. Os alérgenos que determinaram maior positividade foram poeira + Dermatophagoides, Dermatophagoides sp. e Dermatophagoides pteronyssinus.

\section{Referências bibliográficas}

1. Homburger HA, Katzmann JA. Methods in laboratory immunology. In: Middleton Jr E, ed. Allergy - Principles and Pratice. St. Luis, Missouri, USA: 1993, p.554-72.

2. Santos MA, Lerner AP, Castro FFM. Diagnóstico clínico e laboratorial das rinites alérgicas. In: Castro FFM, ed. Rinite Alérgica. Modernas abordagens para uma clássica questão. São Paulo: Lemos Editorial; 1997. p.48-61.

3. Halasz MR, Gonsales SL, Solé D, Naspitz CK. Specific sensitization to Dermatophagoides pteronyssinus and cutaneous reactivity to histamine in Brazilian children. J Investig Allergol Clin Immunol 1997; 7:98-102.

4. Skassa-Brociek W, Manderscheid J-C, Michel F-B,Bousquet J. Skin test reactivity to histamine from infancy to old age. J Allergy Clin Immunol 1987; 80:711-16.

5. Tariq SM, Mattheus SM, Stevens M, Hakin EA. Sensitization to Alternaria and Cladosporium by the age of 4 years. Clin Exp Allergy 1996; 26:794-8.
6. Halonen M, Barbee RA, Lebowitz MD, Burrows B. An epidemiologic study of the interrelationships of total serum immunoglobulin E, allergy skin test reactivity, and eosinophilia. J Allergy Clin Immunol 1982; 69:221-28.

7. Geller M, Esch RE, Fernandez-Caldas E. Respiratory atopy and domestic mite sensitization in Rio de Janeiro. Rev Bras Alerg Imunopatol 1995; 18:13-8.

8. Rizzo MC, Fernandez-Caldas E, Solé D, Naspitz CK. IgE antibodies to allergens in allergic children in São Paulo - Brasil. J Invest Allergol Clin Immunol 1997; 7:242-48.

9. Bernd LAG, Baggio D, Becker AB, Ambrozio LC. Identificação e estudo da atividade sensibilizante de ácaros domésticos em Porto Alegre - RS. Rev Bras Alerg Imunopatol 1994; 17:23-33.

10. Sarinho E, Fernandez-Caldas E, Just E, Solé D. Ácaros da poeira domiciliar em residências de crianças asmáticas e controles da Cidade de Recife - Pernambuco. Rev Bras Alerg Imunopatol 1996, 19:228-30.

11. Solé D, Carneiro-Sampaio MM, Naspitz CK. Serum levels of immunoglobulins ( $\mathrm{G}, \mathrm{A}, \mathrm{M}$ and $\mathrm{E}$ ) in patients with respiratory allergy. AMB Rev Assoc Med Bras 1985; 31:236-40.

12. Demoly P, Bousquet J, Menderscheid JC, Dreborg S, Dhibert H, Michel FB. Precision of prick and puncture tests using nine methods. J Allergy Clin Immunol 1991; 88:758-62.

13. Aberer W, Kranke B, Hager A, Wick G. In vitro allergy testing needs better standardization tests results from different laboratories lack compatibility mostly due to missin effective standards. Int Arch Allergy Immunol 1995; 108:82-8.

14. Clarke CW, Mitchell J, Nunn AJ, Pepys J. Reproducibility of prick skin tests to five common allergens. Clin Allergy 1982,12:1-8.

15. Vichyanond P, Nelson HS. Effect of circadian variation of skin reactivity on allergy skin tests results (abstract). Ann Allergy 1988; 60:154.

16. Slott RI, Zweiman B. A controlled study of the effect of corticosteroids on immediate skin test reactivity. J Allergy Clin Immunol 1974; 54:229-34

17. Cook TJ, MacQueen PM, Witting HJ, Thornby JI, Lambos RL, Virtue CM. Degrees and duration of skin test supression and side effects with antihistamines. J Allergy Clin Immunol 1973; 51:71-7.

18. Harvey RP, Schocket AL. The effect of $\mathrm{H} 1$ and $\mathrm{H} 2$ blockade on cutaneous histamine response in man. J Allergy Clin Immunol 1980; 65: 136-9.

19. Forte WCN, Almeida AR, Leão RC. Resposta fagocitária e atividade quimiotática de leucócitos mononucleares em crianças eutróficas. Rev Hosp Clin Fac Med S Paulo 1990; 45:256-9.

20. Forte WCN, Ruiz RC, Vendrame CMV, Guedes MLS, Mimiça I, Leão RC. Contagem de linfócitos timo dependentes e bursa equivalentes em crianças normais. J Pediatr (Rio J) 1991; 67: 227-30.

21. Eriksson NE, Holmen A. Skin prick tests with standardized extracts of inhalant allergens. J Investig Allergol Clin Immunol 1996, 6:36-46.

22. Yabuhara A, Macaubas C, Prescott SL, Venaille TJ, Holt BJ, Habre W, et al. TH-2 polarized immuological memory to inhalant allergens in atopic is estabilished during infancy and early childhood. Clin Exp Allergy 1997; 27:1261-9.

23. Barbee RA, Brown WG, Kaltenborn W, Halonen M. Allergen skin-test reactivity in a community population sample: correlation with age, histamine skin reactions, and total serum immunoglobulin E. J Allergy Clin Immunol 1981;68:15-9.

Endereço para correspondência:

Dra. Wilma Carvalho Neves Forte

Rua Al. Manacás, 407 - Residence Park - Granja Viana

Cotia - SP - CEP 06700-000

Fones: (11) 492.2542 / 226.7311 